Revista Iberoamericana. Vol. LXII, Núms. 176-177, Julio-Diciembre 1996; 767-779

\title{
CONSERVADURISMO Y DISENSIÓN: \\ EL SUJETO SOCIAL (MUJER/PUEBLO/ETNIA) \\ EN LAS NARRATIVAS REVOLUCIONARIAS
}

\author{
POR \\ Ileana Rodriguez \\ The Ohio State University
}

EL YO-(NOSOTROS) DESDE LA DIFERENCIA

En una reseña que escribió David Brion Davis sobre Eugene D. Genovese, decía que el paralelismo entre el socialismo y el conservadurismo sureño, basado en la esclavitud, no termina con su abierta hostilidad contra el individualismo irresponsable y el dominio de los valores del mercado, sino que viene a ser la representación de la disensión de los dos grandes enemigos del gran sistema norteamericano. ${ }^{1}$ Los términos conservadurismo y disensión se utilizan en este contexto como estrategias para homologar formas operativas de gobernar, en las cuales un grupo ejerce su hegemonía cultural e intelectual sobre un territorio, a costa de lo que puede pensarse como "el interés nacional" (democracia), en este caso, el de los Estados Unidos. Un estudioso de la esclavitud como Genovese, continúa Brion Davis, que sabía que la causa del Sur estaba perdida, todavía albergaba ilusiones de que su análogo, el socialismo, pudiera redimir la humanidad y sólo tiempo después "enfrentó el costo humano sin precedente del movimiento para crear la utopía socialista" (44). Ya claramente situado no tanto en el post-marxismo cuanto en el post-sovietismo, Genovese concede que ni aun las atrocidades de los esclavistas pueden igualarse a aquéllas "de nuestro propio romance con la utopía de un cielo en la tierra hecho por el hombre empapado en sangre" (44).

Resulta un poco dramático, y hoy sin duda explicable aunque exagerado, comparar el conservadurismo de los esclavistas sureños con el del Partido Comunista soviético, pero yo quiero utilizar este despegue, que contrasta partidos, gobiernos, naciones y momentos disímiles, para presentar, desde las ideologías del socialismo y la revolución, cuatro tensiones en la constitución del sujeto popular subalterno (mujer/pueblo/etnia como lo subyugado), que ilustran la permanencia de ideas conservadoras, en el sentido del individualismo señalado arriba, dentro del pensamiento revolucionario en las narrativas de sus dirigentes. Quiero argumentar que la presencia de lo conservador, dentro de un gobierno que se predica como radical, tiene como contrapartida la disidencia. La primera tensión tiene que ver con la constitución de un sujeto que se presenta a la vez como individual y colectivo, un yo que se inscribe como nosotros. La segunda es un corolario de la primera

\footnotetext{
' David Brion Davis, "Southern Comfort". The New York Review of Books (October 5, 1995) 43-46. A menos que sea indicado lo contrario, todas las traducciones son mías.
} 
y tiene que ver con las condensaciones metafóricas de mismidad, alteridad, neutralidad, en el sentido que las usa Jacques Lacan. La tercera puede inscribirse como la idea del cambio representada como tránsito entre el discurso masculino y el femenino y postétnico. La cuarta es la de las analogías entre tiranía y patriarquía, que colocan al sujeto popular subalterno (mujer/pueblo/etnia) en el lugar de lo subyugado.

En la constitución de lo nuevo, primero como masculinidad, como "hombre nuevo", después como diferencia entre dos masculinidades, una romántica burguesa y liberal, y la otra radical, se encuentra un primer tropiezo en el pensamiento revolucionario. Esta estrategia discursiva constituye un dominio que excluye lo femenino y lo étnico, y localiza, dentro de la construcción de las utopías, una segregación conservadora anti democrática. El discurso feminista y étnico, por el contrario, al hablar en nombre de grandes sectores poblacionales antes excluidos, es más inclusivistay democrático. La orientación acríticamente masculina del discurso revolucionario, es una rúbrica que (re)produce ideas liberales, en ese momento señaladas como un horizonte histórico conservador, e indica, para los radicales, un punto de desacuerdo consigo mismo, lugar donde la democracia y el pluralismo se convierten en oposición.

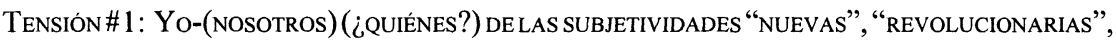
Y VIEJAS, ROMÁNTICAS.

La constitución de la subjetividad "nueva" del "hombre nuevo" de los revolucionarios, se instala en el texto de los revolucionarios como diferencia entre dos tipos de masculinidad, una conservadora (liberal) y la otra radical. El punto de comparación es la subjetividad producida por el Romanticismo, un yo individualista (liberal). En su libro sobre el Romanticismo, Susan Kirkpatrik describe el dominio donde operan los parámetros de esta formación de la ontología masculina-burguesa-individualista. ${ }^{2}$ Basándonos en su estudio, podemos argumentar que el individualismo burgués es a la vez el punto de despegue y convergencia para ese yo del "hombre nuevo" que propone el Che, ya que los atributos de lo nuevo se parecen mucho a los de lo viejo que quiere trascender. Dónde se separan y dónde convergen estas dos ontologías, es lo que voy a argumentar, pues aquí estamos frente a una disyuntiva que funde lo sociológico (el deseo de representar al colectivo), con lo psicológico (el deseo de autorrepresentarse), esto es, el momento de la trascendencia del individualismo que quiere disolver el yo en el nosotros, borrar el trazo, como diría Derrida, de lo conservador en lo radical.

En las narrativas revolucionarias, por ejemplo en los textos de Tomás Borge, de Omar Cabezas, en los del Che Guevara, se nota la tensión entre cómo hablar en nombre propio y, a la vez, en nombre del colectivo; o, cómo hablar en el nombre del colectivo como partido político (por ejemplo en los discursos de Fidel Castro), y cómo hablar en nombre de la sociedad, de la nación, del pueblo. En todos estos escritos, la permanencia de lo "psíquico", o la fuerte marca individual, impide alcanzar la mismidad entre el yo y el colectivo, el yo y el grupo social más amplio, sea este clase, organización, frente, partido, masas, pueblo, tropa, bases.

${ }^{2}$ Susan Kirkpatrick, Las Románticas: Women Writersand Objectivity in Spain, 1835-1850 (Berkeley, Los Angeles, London: University of California Press, 1989). 
Para marcar la "diferencia" entre lo conservador y lo radical, habría sido más provechoso explicar en qué radicaba la "diferencia" como otredad, como lugar de lo subyugado (mujer/pueblo/etnia), y quizás eso pretendían los dirigentes cuando hacían análisis de clase y mencionaban los sectores sociales a quienes ellos (la vanguardia, el partido), iban a gobernar. La diferencia estaba marcada por la clase, burgués o proletaria - los trabajadores, los campesinos. Para el Che el "hombre nuevo" era una opción por el pueblo. Este "hombre nuevo" era todo resistencia, serenidad, aguante, amor, es decir, aquéllas virtudes que le permitían luchar por los pobres. ${ }^{3}$ Pero todos estos atributos eran ya del dominio del yo romántico burgués. ${ }^{4}$ En mi libro sobre mujeres, guerrillas y amor, he argumentado que todos estos ejemplos estaban predicados dentro de los marcos inertes de las epistemologías conservadoras, la principal de las cuales era la patrística. ${ }^{5}$ De todos los revolucionarios, sólo Sergio Ramírez se dió cuenta del vacío del concepto pueblo como "campesino", al comparar la imagen del "hombrecito" campesino a la del dirigente "hombre nuevo". Eran esas dos imágenes representantes de mundos radicalmente opuestos, dos imaginarios sociales paralelos. Ramírez expresa su azoro ante el reconocimiento del desconocimiento que el Partido, y él mismo en particular como intelectual, tienen de ese "hombrecito", sujeto campesino en el nombre del cual el radicalismo revolucionario hablaba. ${ }^{6}$ Por eso las epistemologías feministas argumentan que la construcción de esa subjetividad "nueva", tema como prerrequisito el examen de la lógica de la construcción de la mismidad, de la neutralidad y de la diferencia, tensión 2) que veremos abajo.

Para borrar la diferencia entre el yo y el nosotros, había que entender lo otro (como subyugado) desde dentro. En su libro sobre insurgencias campesinas, Ranajit Guha propone una serie de categorías esenciales, entre ellas, la de negación. Negación no sólo es entender que la conciencia del subalterno se construye como y desde el no, sino también un método, el de leer a contrapelo. ${ }^{7}$ Porque es en la negatividad donde ocurren los sincretismos y las conflagraciones (mujer/pueblo/etnia). Había, por tanto, primero que negar para después afirmar. El primer paso era sacar lo otro subyugado del lugar donde había sido remitido anteriormente. En el caso de mujeres y etnias, leer a contrapelo dos grandes narrativas, las de la biología y las de la patrística, una que explica la subyugación como "natural", y la otra como "moralidad". Había que negar la categoría "mujer" e inventar la de "género". Para poner un ejemplo, mostrando las limitaciones de las determinaciones bio-sexuales, Teresa de Lauretis intenta una definición pidiendo dos préstamos, uno a Foucault y el otro a Althusser. Del primero toma la noción de efecto y del segundo la de ideología. Género es así "el conjunto de efectos producidos en los cuerpos, comportamientos,

\footnotetext{
${ }^{3}$ Ernesto Che Guevara, La guerra de guerillas (Havana: Ciencias Sociales, 1972); El diario del Che en Bolivia (Havana: Instituto del Libro, 1968).

${ }^{4}$ Terry Eagleton. The Rape of Clarissa (Minneapolis: University of Minnesota Press, 1982).

${ }^{5}$ Ileana Rodríguez, Women, Guerrillas, and Love: Unverstanding War in Central America (Minneapolis: University of Minnesota Press, 1996).

${ }^{6}$ Sergio Ramírez, Confesión de Amor (Managua: Ediciones Nicarao, 1991).

7 Ranajit Guha, Elementary Aspects of Peasant Insurgency in Colonial India (Delhi: Oxford University Press, 1983).
} 
y relaciones sociales"; o, "las relaciones imaginarias de los individuos con las relaciones reales de su existencia" (de Lauretis 35-36). ${ }^{8}$

Katharine MacKinnon, por su parte, propone que para conocer eso desconocido, hay que hacer entrar las epistemologías maestras en el domus y domesticarlas, poner en escena la voz argumentativa del logos femenino negado, logos en el cual el sujeto femenino de la interlocución argumenta repitiendo las mismas premisas al revés y haciendo de la tautología y la redundancia, visibilizaciones y comparecencias. En la lógica del absurdo o en la reducción al absurdo de la lógica de las certezas masculinas respecto a lo otro femenino subyugado, se encuentra lo otro femenino subyugado. Por ejemplo, la proposición de que en la mujer no se niega la diferencia biológica sino que se niega la diferencia como biológica. MacKinnon afirma que,

Si el género es una categoría social, el género es lo que sea que él signifique socialmente. Todas las mujeres serán o no afectadas de manera particular por esta realidad de género, la totalidad de lo cual comprende el significado de género como categoría social .. demostrar que una observación o experiencia no es lo mismo para todas las mujeres sólo prueba que no es biológica, no que no es de género. De manera similar, decir que no todas las mujeres experimentan lo mismo ... sólo sugiere que el estatus de la mujer no es biológico. ${ }^{9}$

Persiguiendo el mismo objetivo, al referirse a ambos, Jean François Lyotard y su metadiscurso, Alice Jardin sostiene que él lo define como "un discurso 'funcional-deverdad' - esto es, como un discurso que se autoriza a sí mismo a decir lo que dice como verdad". ${ }^{10} \mathrm{Y}$ cuando de Lauretis se pregunta:

Si el género existe en la "realidad", si existe en "las relaciones reales que gobiernan la existencia de los individuos", pero no en la filosofía o la teoría política, qué es lo que el último de hecho representa sino "las relaciones imaginarias de los individuos a las relaciones reales en las que viven?" (6).

Estas tres incursiones del feminismo en las lógicas maestra, y su estrategia de domesticación, encuentran el absurdo. Las lógicas maestras (romanticismo burgués/ patrística), incluyen dentro de estos absurdos la construcción de la diferencia como vacío. Los revolucionarios llenan este vacío con otras narrativas maestras. En el proceso de semiósis de la escritura, la definición de mujer, de etnia, de pueblo es una ausencia, un sinsentido. ¿Cómo, entonces, proponer constituir a partir de ese vacío el colectivo?

Por su parte, adentrándose en la constitución del sujeto popular como gaucho, Josefina Ludmer muestra las "diferencias" del gaucho como diferencia. " Ella desconstruye el sujeto

\footnotetext{
${ }^{8}$ Teresa de Lauretis, Technologies of Gender: Essays on Theory, Film and Fiction (Bloomington and Indianapolis: Indiana University Press, 1987).

${ }^{9}$ Katharine MacKinnon, Feminism Unmodified. Discourses on Life and Law (Cambridge: Harvard University Press, 1987).

${ }^{10}$ Alice Jardine, Gynesis: Configurations of Woman and Modernity (Ithaca and London: Cornell University Press, 1985).

"Josefina Ludmer, El género gauchesco: Un tratado sobre la Patria (Buenos Aires: Sudamericana, 1988).
} 
"gaucho" dentro de la gauchesca y muestra el lugar del gaucho en la construcción letrada como el lugar de lo subyugado. El develamiento de la figura del gaucho en la sintaxis letrada y su reproducción por el corpus de las letras argentinas, echa luz sobre el gaucho como sujeto de opresión y muestra cómo la cultura letrada ejerce su poder sobre este colectivo gaucho al apropiárselo como sujeto en la escritura. La escritura escinde al gaucho literario del gaucho como sujeto social y, por ende, al gaucho como sujeto social del escritor como sujeto social en la construcción de la patria. Ludmer devela al gaucho como un momento continuo de la representación de las masas-pueblo del colectivo tan buscado, de lo subyugado construido en el ejercicio del poder como grafía. De la misma manera que el sujeto femenino se hace visible lógicamente en la escritura feminista, el gaucho (análogo de femenino/etnia subyugado), emerge en esta escritura sobre la patria. En la lógica se visibiliza el vacío de la construcción letrada. En las epistemes y métodos feministas, además de los vacíos de las lógicas maestras, emerge, en la lógica del oprimido, el oprimido.

Estos ejemplos me sirven para argumentar, con y como ellas, a contrapelo; me permiten afirmar que el sujeto sexuado universal, en este caso el "hombre nuevo", no es el sujeto neutro de la representación y la comunicación de todo el colectivo, sino un sujeto masculino individual - Che, Cabezas. La lógica de la diferencia practica la construcción del sujeto "de la diferencia" (mujer/pueblo/etnia) como diferencia. Lo que la diferencia en-gendra es un sujeto femenino/popular/étnico y los problemas que tal sujeto sexual y popular produce como sujeto del habla. Pero también demuestra que este sujeto de la diferencia resulta más inclusivo y abarcador, es decir, el camino más corto entre el yo y ese nosotros buscado por esas democracias populares representativas.

La inserción de lo femenino como diferencia tiende, en el espacio de lo masculino, hacia el espacio del poder doméstico. Las mujeres escogen el espacio de la familia (la casa) para argumentar su propia negación dentro del espacio estatal patrio. En la casa, que es el dominio de la familia, está el padre/poder; en el Estado, la patriarquía/tiranía. Ambos, casa/ Estado, son sitios de lucha y resistencia. En el texto de Gioconda Belli, esta lucha se produce en la inclusión de la resistencia indígena como resistencia de género; en el de Gloria Guardia, el de la mujer/varón emancipada; en el de Yolanda Oreamuno, el del hombre/mujer y la mujer/hombre. ${ }^{12}$ En las tres, esta resistencia denodada se inscribe en un espacio disidente. En los símbolos del árbol, la india, la madre, la semilla, el gérmen, se localiza la idea de la mujer una vez más como naturaleza, pero en estos símbolos la mujer se auto-constituye en perpetuo diálogo textual/sexual con todos, realizando así un circuito inverso al del hombre que sólo dialoga con los hombres. En estos diálogos de valencias opuestas, lo femenino quiere negociar; lo masculino, excluir $-\mathrm{y}$ si forzado, sectorializar.

La presencia femenina en la escritura revolucionaria femenina mater(ializa), hace suya la realidad material, imagina y recrea la materia para reconstruirla y transformarla. La tensión tiranía/patriarquía es uno de los objetos favoritos de tal representación en la literatura de mujeres. Aparentemente, las mujeres proponen una distensión del sistema patriarcal, mostrar en sus textos el lugar del nosotros subyugado. La mujer no puede glosar

${ }^{12}$ Gioconda Belli. The Inhabited Woman. Kathleen March, trans. (Connecticut: Curbston Press, 1994); Gloria Guardia, El último juego (San José: EDUCA, 1977); Yolanda Oreamuno, La ruta de su evasión (San José: EDUCA, 1984). 
el colectivo puesto que ese es su propio lugar. Las mujeres asumen la idea de la colectividad como pueblo y hasta como organización, a fin de crear su propia definición de ser, aun si ésta, como en el caso del Romanticismo que apunta Kirkpatrik, es también de clase.

En el debate contra la idea de que la función de la mujer en la pareja es servicio o violación (visión revolucionaria de la pareja), las mujeres entran en diálogo con las estructuras del patriarcado. En las analogías entre oligarca/padre/marido y pueblo/hijos/ mujer, se reproducen las fuerzas y las hegemonías estatales a fin de confrontarlas. En la escritura femenina, la mujer combate el patriarcado déspota, absoluto, modelo y episteme del poder masculino (tiranía), que ahoga todo intento de formación del nosotros, incluso en la instancia más pequeña e individual que es la pareja. Las narrativas femeninas revolucionarias son narrativas en las que la pareja patriarcal es disfuncional.

El yo femenino, representado en y por el texto revolucionario femenino, es el de la mujer/escritora en proceso (en el sentido legal que Kristeva da al término: juicio y prueba) de auto-construcción y sus efectos colaterales. El yo masculino representado en el texto "revolucionario" masculino es el de la reproducción del ego masculino y, por ende, el de su separación del colectivo. En la contraposición hombre/mujer como oposición hombre/ mujer se encuentran las primeras tensiones. Es, según Lacan, el caso de la metáfora que condensa:

Verdichtung, o "condensación”, es la estructura de la superimposición de los significados, que la metáfora toma como su campo, y cuyo nombre, condensando en sí misma la palabra dichtung, muestra cómo el mecanismo es connatural con la poesía (Lacan 160). ${ }^{13}$

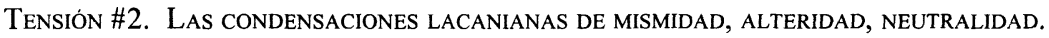

En esta condensación vendrá a radicar la segunda tensión, la de la mismidad como alteridad y como neutralidad. La constitución del yo como nosotros en base a la mismidad (entre yo y el otro del nosotros), y a la neutralidad (en el yo-(nosotros) de la supuesta incorporación de lo femenino/popular/étnico), condensó una y la misma idea en tres palabras diferentes. Lo mismo vino a ser el mismo yo masculino, hombre, en el sentido genérico del término, sexualidad en la clase, sectorialidad sexualizada. Esto es, la prolongación de lo "universal" de la cultura logo y falocéntrica. En esta mismidad pervive el conservadurismo que alimenta la disidencia.

Esta tensión, la de la idea de la conflagración yo-(nosotros) como mismidad, como neutralización de la "diferencia" (masculino/femenino, mujer/pueblo/etnia), o como condensación, metáfora de la alteridad (cuando digo hombres significo hombres y mujeres), sitúa al sujeto "nuevo" en el mismo lugar del sujeto viejo y le permite ejercer, desde la misma posición de sujeto anterior, la autoridad y el poder (la patriarquía como tiranía) de la misma manera que lo ejercía el sujeto viejo y sobre lo mismo subyugado anterior (lo femenino/ popular/étnico). Lo subyugado, sin embargo, continúa existiendo como huella, como vacío de representación, como subjetividad desconocida y reprimida. Se aplica aquí entonces lo que Foucault dice sobre la posición del sujeto como asignada:

${ }^{13}$ Jacques Lacan, Ecrits. A Selection (New York: W.W. Norton \& Company, 1977). 
El sujeto de la afirmación no debe ser visto como idéntico al autor de la formulación. No es ... la causa, origen, o punto de partida del fenómeno de la articulación de la oración escrita o hablada ... no es la arena constante, inamovible de una serie de operaciones .... Es un lugar determinado y vacante que puede ser ocupado por individuos diferentes (Foucault 95-96). ${ }^{14}$

Ampliando esta observación Spivak señala agendas conservadoras en el desconocimiento de esta propuesta:

La particularidad de este espacio - “yo" es un signo. Puede por ejemplo significar una proveniencia sociopolítica, sico-sexual, institucional-disciplinaria o económico-étnica. De aquí que Foucault use la palabra "asignada": "la posición del sujeto puede ser asignada" (Spivak 243). ${ }^{15}$

O sea que entre el yo (sujeto del individualismo romántico burgués - liberal) y el nosotros (sujeto del colectivo revolucionario - radical) debería haber una fractura, una discontinuidad y, potencialmente, un conflicto insalvable. Pero, en vez de ese, hay una solidaridad entre afines. Hay un objeto de deseo de hombría homosocial, un narcicismo masculino. La epistemología revolucionaria se aboca a construir el puente como suplemento, como adenda, pero el puente lo constituye entre el hombre viejo y el hombre nuevo. Para salir de ese desideratum, los revolucionarios propusieron la escritura de narrativas sectoriales, narrativas exclusivas para mujeres, para campesinos, para etnias.

Pero las discontinuidades que tienden a suplir las narrativas sectoriales son similares a las que Freud establece entre consciente e inconsciente, o a las postulaciones del cuerpo de Kristeva como "la emergencia de lo semiótico en lo simbólico" (Kristeva 217). ${ }^{16}$ De ahí el análogo del sujeto femenino/popular/étnico con el inconsciente y con el pueblo, con lo subyugado, de lo cual resulta la segunda exclusión u otra manera de ver la misma exclusión, la exclusión de la mujer (sujeto popular subyugado), que no pueden "copiar" las epistemes de la diferencia planteadas como la formación del "hombre nuevo". Porque esta diferencia no es la misma "diferencia" de la que hablan las epistemologías feministas y que veremos después, sino diferencias masculinas entre seres masculinos, conservador y radical, esto es mismidades, no diferencias.

El sujeto femenino/popular/étnico (lo subyugado) tampoco puede inscribirse en esta mismidad y esta neutralidad porque eso equivale a valorarse con criterios masculinos de poder. Al respecto MacKinnon dice:

Nuestro alegato no es la diferencia de género sino la diferencia que significa el género, el sentido social impuesto sobre nuestros cuerpos .... La igualdad es una equivalencia, no una distinción, y el sexo es una distinción. El mandato legal de trato igual — que es tanto

\footnotetext{
${ }^{14}$ Michel Foucault, The Archaeology of Knowledge and the Discourse on Language. M. Sheridan Smith, trans. (New York: Tavistock, 1972).

${ }^{15}$ Gayatri Spivak. In Other Worlds. Essays in Cultural Politics (London \& New York: Routledge, 1988).

${ }^{16}$ Julia Kristeva, "The Speaking Subject”. In Marshall Blonsky, ed., On Signs (Baltimore: The Johns Hopkins University Press, 1985) 210-220.
} 
una norma sistémica y una doctrina legal específica, viene a ser asunto de tratar igual a los iguales y desigual, a los desiguales; y los sexos son definidos por sus desigualdades mutuas. Dicho de otra manera, el género es socialmente construido como epistemológicamente diferente; la ley de la discriminación sexual ata la igualdad de género a la diferencia doctrinaria ... [un] concepto de igualdad, que presupone mismidad, y este concepto de sexo, que presupone diferencia (MacKinnon 23-24).

Dentro de esta lógica hegemónica, la escritura revolucionaria femenina textualiza la búsqueda de ese ser "otro" que, organizado por otras grafias, introduce la necesidad de lo que de Lauretis llama el estudio de códigos pre-establecidos, cuyos signos ordenados producen significados patrón. Es en este sentido que la literatura escrita por mujeres tiene una intersubjetividad fluida, en la que se inmiscuyen y colapsan, se intercodifican, también, como dice Jameson "los sujetos narrativos, fictivos y biográficos", y en los que, como en su análisis de La vielle fille, una inversión de deseo o fantasía disuelve lo biográfico en lo utópico (Jameson 169). ${ }^{17}$

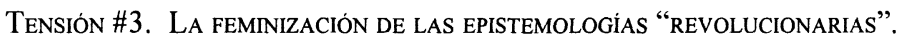

La tercera gran tensión es la de la feminización (reprimida) de las epistemologías revolucionarias, o sea, la verdadera revolución respecto a las epistemes románticas y el real tránsito entre unas y otras. Este lugar se escribe como disidencia.

En la idea del tránsito del yo al nosotros encontramos una sorpresa, una zozobra, algo "rarísimo". Fidel Castro y Raúl Roa afirman que ésta era una característica del Che. ${ }^{18}$ Para mí eso "rarísimo", una aureola, es la feminización de las epistemes revolucionarias: feminización en su metáfora esencial de la Montaña como sincretismos de lo masculino/ femenino; en la formación del campamento guerrillero como domus, casa y domesticidad del hombre con el hombre; en la construcción del líder como "stabat mater"; en la obvia representación de lo subyugado como mujer y mesa; en la sensibilización del agente masculino en la Montaña; y en la fundamental adhesión al Mater(ialismo) y la dialéctica que es, en lo esencial, respeto al principio de oposición. Este tránsito podría postularse como desplazamiento. Según Lacan:

Verschiebung, "desplazamiento", el término alemán es más cercano a la idea de virar la significación que vemos en la metonimia, y la cual, desde su aparición en Freud, se representa como el medio más apropiado usado por el inconsciente pare engañar la censura (Lacan 160).

Tensión \#4. Tiranía/Patriarquía: Pueblo-Masa-Tropa-Base. Lo subyugado.

Dentro de este sistema de signos pre-establecidos, y la interferencia en ellos de lo femenino, quiero prestar especial atención a lo que creo constituye el signo esencial del

${ }^{17}$ Fredric Jameson, The Political Unconscious: Narrative as Socially Symbolic Act (Ithaca: Cornell University Press, 1981).

${ }^{18}$ Fidel Castro, “¡Hasta la victoria siempre! En Ernesto Che Guevara”. La guerra de guerillas (La Habana: Ciencias Sociales, 1972). 
error, o la mayor tensión sumergida de las escrituras revolucionarias, esto es, las de copiar el conjunto de metáforas cuyos vehículos de tirano-tiranía/padre y esposo-patriarquía lugares nominales de lo masculino y de lo individual; y los tenores pueblo, hijo y esposalugares nominales de lo "otro" como lo femenino y lo colectivo- colocan a éstos últimos en los lugares de lo subyugado y, por tanto, del cambio y, sobre todo, del radicalismo de lo "nuevo".

Las escrituras revolucionarias, al parecer, no se movieron de la primera a la segunda posición sino que emitieron desde las primeras posiciones institucionales de un sujeto ya hegemonizado. Y en este caso fueros escrituras alegóricas de las narrativas maestras. En el caso del Che, lo revolucionario como patrística. O sea que no sólo no ejercieron el criterio radical sobre lo pre-codificado por la literatura anterior conservadora y burguesa, sino que tampoco prestaron especial atención a las cuestiones de otro género, pues era en el lugar de lo femenino/pueblo/etnia donde se podía localizar la acción revolucionaria radical.

La construcción de lo "nuevo" colectivo "revolucionario" es, desde el punto de vista epistemológico, esencialmente oximorónica. La paradoja radica, por un lado, en postular lo "nuevo", primero, como atributo masculino (dictaduras de la burguesía o del proletariado) y, por ende, a asumir la igualdad entre desiguales: yo/pueblo, nosotros partido/masas populares. En esto "nuevo", la mujer no es compañera sino "ribera de su río"/"reposo del guerrero", esto es, doméstica. Esto significa asumir acríticamente el paradigma de subjetividad de género femenino que el Romanticismo edificó para la mujer. Asumiendo que femenino y popular constituyen parentescos, al negar a la mujer el atributo de compañera, se glosa a la vez el del pueblo como sujeto subyugado. Así las analogías tiranía/ patriarquía - como lo no democrático- y las de patria y potestad masculinas quedan reinstituidas. La serie niños, mujeres, ancianos y lisiados de guerra, frase hecha que se reitera en los panfletos precedido por el adjetivo posesivo "nuestros", como sujetos de la enunciación de lo que hay que proteger en las escrituras políticas revolucionarias, sólo deja al margen la categoría central de hombre, y de hombre en edades entre la niñez y la ancianidad.

Viene aquí bien traer a colación la polémica feminista sobre género como diferencia. Teresa de Lauretis considera que la noción de "género, como diferencia sexual ... ha devenido ahora una limitación" porque constriñe

el pensamiento crítico feminista al marco conceptual de una oposición sexual ... hace muy difícil, sino imposible, articular las diferencias de las mujeres de la Mujer ... las diferencias entre las mujeres ... las diferencias dentro de las mujeres (de Lauretis 1-2).

Y un segundo límite, dice, es el de reconcentrar "el potencial epistemológico del pensamiento feminista dentro de las paredes de la casa del amo" (2).

Esta inquietud sobre la relación género/diferencia/sexualidad, o entre Mujer como el objeto y la condición de la representación, "y las mujeres" seres históricos sujetos a "relaciones reales", es formulada por Alice Jardin como “'de mujer' o 'lo femenino' como ambos, metáfora de la lectura y topografía de la escritura para confrontar el colapso de la metáfora paterna" (Jardin 34). 
La problematización del significado "mujer" como lo doméstico, una inclusión de la mujer en la biología, que vimos arriba, y su representación como "proceso que rompe las estructuras simbólicas de Occidente" (Jardine 42), vino a instalarse dentro de las epistemologías revolucionarias como disidencia. Mujer era sólo aquello que permitía la "contemplación" masculina - "ribera de su río", "reposo del guerrero". Así aparece por lo menos en el pensamiento testimonial. ${ }^{19}$

Hemos repetido hasta el cansancio cómo la concepción de sujeto revolucionario se constituía como una diferencia en relación a la constitución del sujeto burgués y cómo esta diferencia presumía la identidad del yo y el nosotros, su simbiosis en la dialéctica de la igualdad. Más también apuntábamos cómo la transacción entre esos dos sujetos separaba líder de pueblo (lugar de lo femenino) y asumía una identidad/igualdad basada en esa distinción. En cuanto a las mujeres, el concepto de colectivo era excluyente. Fue en la prosa política, en trabajos apartheid dedicados exclusivamente a la mujer, que se empezó a constituir el sujeto de género como neutralidad.

En la escritura revolucionaria, en general, se asume la posición de sujeto masculino como paradigma de los dos (condensación metafórica lacaniana), el hombre y la mujer. En el tránsito entre ese yo individual y ese nosotros colectivo (mujer/pueblo/etnia) la agencia es de amor, pero el amor transformador, la ternura, es concebido ya como tendresse homosocial - relación hombre-hombre en el partido-, o como intransigencia disciplinaria (tiranía/patriarquía). Este es el caso del concepto "hombre nuevo" en Cabezas. ${ }^{20}$ Desde una y otra villa encontrábamos que los conceptos excluían de las topografías de las narrativas revolucionarias a las mujeres "reales", y que lo femenino, como representación de la mujer, "aquello" que permitió la "contemplación" masculina, experimentaba un tratamiento confuso, una simbiosis en la Montaña, como sitio de producción patriótica y metáfora de relación erótica. No obstante, la confusión de todas las relaciones filiales primarias en un mismo sitio y con un mismo referente, que podían considerarse como principio de cambio, rendían sólo dividendos masculinos.

La escritura revolucionaria nace, entonces, tensionada y eventualmente tiene que desarmar las epistemes de la diferencia sexual edificadas por el Romanticismo (tarea que pretenden las epistemologías feministas) y desestabilizar, por fuerza, cuestiones de hermenéutica referentes a la "mismidad", "neutralidad" o "diferencia" del sujeto revolucionario "nuevo" en cuestiones de género.

Katharine MacKinnon ha demostrado que la "neutralidad" de género es una redundancia. El lugar de la mujer dentro de la legalidad, dice ella, no puede constituirse como subcategoría de la episteme de la neutralidad genérica, pues el modelo de neutro es masculino. En el tratamiento de la "igualdad" ante la ley,

... dos sendas alternas emergen para la igualdad de la mujer ... ser lo mismo que los hombres ... determinada doctrinariamente como neutralidad genérica y estándar único filosóficamente

\footnotetext{
${ }_{19}$ Margaret Randall, Todas estamos despiertas: Testimonios de la mujer nicaragüense de hoy (México: Siglo XXI, 1980); ... y también digo mujer. Testimonios de la mujer nicaragüense hoy (Santo Domingo: Populares Feministas, 1984).

${ }^{20}$ Omar Cabezas, La montaña es algo más que una immensa estepa verde (México, D.F.: Siglo Veintiuno Editores, 1982).
} 
.... [Y] ser diferente a los hombres ... determinada como la regla legal de los beneficios especiales o regla de la protección especial .... Bajo el estándar de la mismidad, las mujeres son medidas de acuerdo con nuestra correspondencia con el hombre.... Bajo los estándares de la diferencia, somos medidas de acuerdo a la falta de correspondencia con él. La neutralidad de género es simplemente el estándar masculino ...: la masculinidad, o lo masculino es el referente de ambas. Aproximar la discriminación sexual de esta manera - como si las cuestiones sexuales son cuestiones de la diferencia y las cuestiones de igualdad son cuestiones de la mismidad - proporciona dos maneras para que la ley sujete a las mujeres a los estándares masculinos y les llame igualdad sexual (MacKinnon 33:34).

La mismidad (igualdad) como neutralidad, y la diferencia como reproducción del género como biología, vienen también a interferir la dinámica presente/futuro de esta literatura y acarrean grandes consecuencias para la representación de la mujer dentro del cuerpo de la ley. Conocidas son las dificultades de esta representación dentro de las legislaciones revolucionarias. Desde el punto de vista de la escritura misma, la metáfora de la escritura como acción constitutiva de un sujeto heroico, viene a formularse como una narrativa a la vez distópica (transformar el conservadurismo presente) y utópica (proyectar la nueva sociedad hacia el futuro radical, i.e., el estado revolucionario). Dentro de esta hermenéutica fundamentalmente proyeccionista y de transformación y autotransformación, era imperativo elaborar el lugar del sujeto femenino/popular/étnico, ya que la escritura política tenía como propósito principal negar esa realidad en la cual las mujeres (pueblo/ etnia) estaban subyugadas, de la cual el texto era su efecto.

Mas la erótica revolucionaria, predicada como una trascendencia sexual (el ascetismo nominal del Che), o como un hom(m)o-sexualismo, dejó que la literatura política mostrara dónde coinciden (mismidad) y dónde se separan (diferencia), lo erótico y lo patriótico en el sujeto revolucionario. Al fusionar lo biográfico (el lugar que autoriza la expresión de lo erótico entendido como sexualidad heterosexual y, consecuentemente, espacio de la mujer) y lo político (lugar donde se permite la expresión de la relación emotiva, entendida como sensibilidad hombre-hombre, la relación (filial) de compañero a compañero y, por tanto, hom(m)o-sexual) priorizó lo último.

Así, al parecer, las narrativas revolucionarias no constituyen un "nuevo" sujeto de género sexual, todavía no definido, sino que se limitan a reproducir el ya inventado por la sensibilidad romántica. La imagen de la mujer, es cierto, sufre un cambio a nivel nominal: de "ángel del hogar", pasa a ser "reposo del guerrero". Pero el cambio de nombres no esconde las semejanzas ni oculta las diferencias. El signo guerrero, junto al de reposo, evocan un espacio general, el del terreno de la guerra (Montaña), del cual está excluida la mujer "real" e incluida su imagen -metáfora de lectura y topografía de escritura, como dice Jardine. El testimonio del Comandante Francisco Rivera, por ejemplo, singulariza la textualización de una sola mujer como sujeto guerrillero. ${ }^{21}$ En ella la valentía, la sangre derramada por las armas (hombría) y la sangre derramada por el cuerpo en la menstruación, se unen en una misma mujer.

\footnotetext{
${ }^{21}$ Sergio Ramírez, La marca del Zorro. Hazañas del Comandante Francisco Rivera Quintero contadas a Sergio Ramirez (Managua: Editorial Nueva Nicaragua, 1989).
} 
Téngase en cuenta que las epistemes de exclusión, cuyas narrativas aquí examinamos, son fuente de legalidad: la legalidad que no asume a la mujer dentro del colectivo, la que no le concede espacio dentro de la acción formadora de ese colectivo, no le adjudica tampoco, por tanto, representación dentro del corpus legal "nuevo". Al no acceder al "terreno de la guerra", al prohibírsele su presencia en ese "algo más qué" y en ese "más allá de", que es la montaña, la mujer queda vedada del acceso al poder (fuente de ley), que emana de la distinción (hombría) en ese terreno vedado. La constitución de la nueva subjetividad, basada en la dinámica de la transformación-auto-transformación (creación del "hombre nuevo"), se forja en el terreno de la guerra, en la Montaña, pero también en la veda y exclusión de la mujer de esa Montaña.

Ya vimos, de pasada, que en la nueva etapa de feminización de la política, en la etapa de la formación de los estados revolucionarios, la Montaña, signo de la patria y, a la vez, metáfora de mujer, es objeto de violación. Las armas, que luego serán sujeto de escritura, excluyen así a las mujeres simultáneamente de las prácticas políticas guerreras y, en la medida que el teatro de la guerra es texto y escritura de la Historia, de las Leyes y de la Literatura, las excluyen de las escrituras de las edificaciones de la utopía, i.e., del futuro y de la legislación de la igualdad del estado "revolucionario".

Desde el punto de vista feminista, la escritura revolucionaria es, entonces, doblemente conservadora. Primero porque se postula como acto de dislocación y desterritorialización $\mathrm{y}$, segundo, porque disloca y escinde el colectivo. La escritura revolucionaria es, así, la escritura de la ilusoria o imaginaria disolución de lo biográfico en lo colectivo o, lo que es lo mismo, de la patriarquía en la democracia y de lo conservador en lo radical.

Quiero sugerir que la presencia de la mujer como cuerpo muerto es la metáfora substitutiva del punto u opción cero de y para la mujer representada, tanto en las literaturas escritas por revolucionarios como en la literatura revolucionaria escrita por mujeres. Si la erotización masculina y la parcial realización del deseo romántico masculino en el heroísmo que ansía la ternura femenina para su reposo, son constitutivas de una literatura de formación nacional burguesa, como Kirkpatrik argumenta, la continua privatización de la mujer y su desvinculación con la lucha, y/o puesta en escena de la mujer muerte, responde a momentos de deformación (nacional). En ellos, la ilegalidad del estatus de la diferencia de género, es metáfora y topos de la deslegitimación del "nuevo" estado revolucionario constituido. Y si la erotización del texto y el uso del amor como argumento entramante son condiciones de la literatura de la formación de los estados nacionales, como Sommer argumenta, la deserotización del texto o la violación y el estupro como edificación textual/ sexual, corresponde a la deformación de la nación, o a la supuesta fundación de la "república revolucionaria" en el rapto, como demuestra Jed para la república romana. ${ }^{22}$

El deseo de patria del guerrillero y su realización por el revolucionario, se va deslizando hacia la representación de los cuerpos muertos: Lavinia en Belli, las mujeres de Oliverio Castañeda en Ramírez; Madame Bovary en Borges; la india y la esposa en Yolanda Oreamuno; la amada en Gloria Guardia; la amiga en Carmen Naranjo; las mesas en Alegría

\footnotetext{
${ }^{22}$ Stephanie Jed, Chaste Thinking: The Rape of Lucretia and the Birth of Humanism (Bloomington
} \& Indianapolis: Indiana University Press, 1989). 
Flakoll. ${ }^{23}$ La letra viene a ser hermenéutica del alegato jurídico, revisionismo histórico, alegato sufragista, o re-escritura irónica del amor burgués. El sujeto femenino constituido por esas literaturas es, pues, desde la mira feminista, objeto de alegato.

La ternura, el descanso y reposo del guerrillero, concebidos como horizonte conservador, se van deslizando hacia lo más temido por el hombre, la desnaturalización del hogar y su abandono. El lenguaje utilizado para esta deserotización no puede, en consecuencia, ser otro que el de la desobediencia civil, la oposición y disidencia.

${ }^{23}$ Claribel Alegría \& Darwin J.Flakoll, They Won't Take Me Alive : Salvadorean Woman in Struggle for National Liberation (London: The Women's Press, 1983); Sergio Ramírez, Castigo Divino (Managua: Editorial Nueva Nicaragua, 1989); Tómas Borge, La paciente impaciencia (Managua: Editorial Vanguardia, 1989); Carmen Naranjo, Diario de una multitud (San José: EDUCA 1984). 
